\title{
Cytokine patterns in paediatric patients presenting serious gastrointestinal and respiratory bacterial infections
}

\author{
ORALIA NÁJERA-MEDINA ${ }^{1}$, MONIKA PALACIOS-MARTÍNEZI', LEONOR RODRÍGUEZ-CRUZ², \\ CONSUELO DEL CARMEN CORTÉS-BEJAR ${ }^{3}$, FERNANDO VALENCIA-CHAVARRÍA ${ }^{3}$, \\ DANIEL MARTÍNEZ-GÓMEZI, MARÍA CRISTINA GONZÁLEZ-TORRES ${ }^{2}$
}

${ }^{1}$ Department of Health Care - Autonomous Metropolitan University - Xochimilco, México

${ }^{2}$ Departament of Health Sciences -Autonomous Metropolitan University - Iztapalapa, México

${ }^{3}$ Xochimilco Maternal and Paediatric Hospital of the Government of Mexico City, México

\begin{abstract}
In the adaptive immune response, the types of cytokines produced define whether there is a cellular (T1) or a humoral (T2) response. Specifically, in the T1 response, interleukin 2 (IL-2), interferon $\gamma$ $(I F N-\gamma)$ and tumor necrosis factor $\beta(T N F-\beta)$ are produced, whereas in the T2 response, IL-4, IL-5, IL6, IL-10 and IL-13 are primarily produced. Cytokines are primarily involved in the regulation of immune system cells. The aim of the present study was to evaluate the cytokine patterns (Type 1/Type 2) and TNF- $\alpha$ expression levels in children with severe gastrointestinal and respiratory bacterial infections. The enzyme-linked immunosorbent assay (ELISA) technique was used to identify the cytokines and the infectious agents. The results obtained demonstrated that, in general, children with bacterial infections experienced an increase in IL-2, IFN- $\gamma$ and IL-4 concentrations and a decrease in TNF- $\alpha, I L-5$ and IL-6 concentrations when compared to healthy children. Specifically, type 1 cytokines and an increased TNF- $\alpha$ concentration were found in children with gastrointestinal infections. However, patients with respiratory infections showed increased concentrations of both $T 2$ (IL-4, IL-6 and IL-10) and T1 (IL-2 and IFN- $\gamma)$ components. Thus, it was concluded that children with gastrointestinal infections exclusively developed a T1 response, whereas children with respiratory infections developed a T1/T2 response to fight the infection.
\end{abstract}

Key words: cytokines, T1, T2, gastrointestinal infections, respiratory infections, ELISA.

(Centr Eur J Immunol 2014; 39 (2): 223-227)

\section{Introduction}

Cytokines are non-antigen specific, soluble factors. They are produced by several cell types and are involved in the regulation of cells in the immune system, inflammatory processes and, occasionally, pathological processes. These molecules exert their functions by acting on specific membrane receptors, initiating signalling cascades that regulate gene transcription, which activates immune system cells [1].

Thus, cytokines influence the activity, differentiation, proliferation and survival of immune cells. They can also regulate the production and activity of other cytokines, which can increase (pro-inflammatory) or decrease (antiinflammatory) the inflammatory response [2].

The adaptive immune response, based on the stimuli received from the innate response, can be directed to either a cellular (T1) or humoral (T2) response type in the defence of the organism. Cells involved in $\mathrm{T} 1$ and $\mathrm{T} 2$ responses undergo a multi-step differentiation process, from a common precursor population, during which a secretion profile of different cytokines is acquired. Specifically, in the $\mathrm{T} 1$ response, the cytokine profile produced includes interleukin-2 (IL-2), interferon $\gamma$ (IFN- $\gamma$ ) and tumour necrosis factor $\beta$ (TNF- $\beta$ ). In the T2 response, the cells primarily produce IL-4, IL-5, IL-6, IL-10 and IL-13 [3].

The aim of the present study was to evaluate the Type 1/Type 2 cytokine patterns and TNF- $\alpha$ expression levels in children with serious gastrointestinal and respiratory bacterial infections and to assess the relationships between the cytokine response and the pathological agents causing the diseases.

\section{Material and methods}

Peripheral blood samples $(3 \mathrm{ml})$ were obtained from paediatric patients ranging from 6 months to 5 years of age, with weights and heights according to their chronological ages. All patients came from the Xochimilco Maternal

Correspondence: Oralia Nájera-Medina, Autonomous Metropolitan University - Xochimilco, Department of Health Care, Calzada del Hueso 1100 Col. Villa Quietud A. P. 23-18, Coyoacán, 04960 México, D. F. México, tel. (52-55) 548375 65, fax: (52-55) 54 83 72 18,

e-mail: onajera@correo.xoc.uam.mx 
and Paediatric Hospital of the Government of Mexico City. The exclusion criteria for all children were as follows: viral diseases, tuberculosis, birth defects, autoimmune diseases, heart disease, birth complications, premature children, transfusions and prolonged drug administration (more than three days) prior to the hospitalisation.

Thirty samples were collected from non-infected children, of whom nine were female, and 21 were male. They were outpatients and attended surgical procedures such as phimosis in the boys or hernias in the girls. Additionally, 30 samples were collected from children with gastrointestinal and respiratory infections, on the day of admission to hospital. Of the infected children, 9 demonstrated gastrointestinal infection, and 21 demonstrated respiratory infection. Twelve of the sick children were female, and 18 were male (Table 1).

Patients with bacterial respiratory infections (pneumonia) had fever, cough and several degrees of respiratory failure. Patients with gastrointestinal infections had diarrhoea, fever and several dehydration levels.

The present study was approved by the Medical Ethics Committee of the Direction of Medical Services of the Government of Mexico City.

\section{ELISA for plasma cytokine determinations}

For the detection of cytokines in the plasma, $1 \mathrm{ml}$ of blood from each child's sample was centrifuged at 1500 rpm for 5 minutes to obtain the plasma. The concentrations of 2 type 1 cytokines (IL-2 and IFN- $\gamma$ ) and 4 type 2 cytokines (IL-4, IL-5, IL-6 and IL-10) were measured; also, the TNF- $\alpha$ concentration was measured. A commercial kit was used to perform the ELISA test (enzyme-linked immunosorbent assay, Peprotech, Inc Rocky Hill, NJ, USA), using the antibody-antigen-antibody methodology [4].

\section{ELISA for the determination of antibodies against infectious agents}

The presence of antibodies against five common infectious agents that are found in the Mexican population was determined in the plasma from both infected and non-infected children using ELISA. In the samples from children with gastrointestinal infections, the presence of antibodies against the outer membrane proteins of two Escherichia coli strains, EHEC (enterohemorrhagic E. coli) and EPEC (enteropathogenic E. coli), was determined. Additionally, the presence of antibodies against the outer membrane proteins of Salmonella typhi was determined. In the samples from children with respiratory infections, the presence of antibodies against Staphylococcus aureus and Klebsiella pneumoniae was determined.

\section{Statistical analysis}

For the statistical analysis of cytokines, a non-parametric test (Mann-Whitney U test) was performed, assuming $p<0.05$ to be statistically significant. For the determination of bacterial agents, a threshold point was established according to Kurstak (1985) [5]. First, the mean and the standard deviation were determined in both groups of patients (infected and non-infected). Then, a range of minimum and maximum values was established for the non-infected patients. All patients exceeding the maximum value were considered positive for the ELISA.

\section{Results}

At the time of hospitalisation haematic biometry showed: in non-infected children the mean haemoglobin concentration was $13.2 \pm 0.5 \mathrm{~g} / \mathrm{dl}$. In infected children it was $13.4 \pm 0.3 \mathrm{~g} / \mathrm{dl}$. The average of total leukocyte counts in non-infected children were 8,200 cells $/ \mathrm{mm}^{3}$, and 13,000 cells $/ \mathrm{mm}^{3}$ for infected children. Percentages of lymphocytes and neutrophils for non-infected children were 47.7 $\pm 2.9 \%$ and $37.6 \pm 2.7 \%$, respectively, and for infected children they were $30.2 \pm 3.2 \%$ and $58.9 \pm 3.8 \%$, respectively.

The cytokine analyses of all the children revealed that the IL-2, IFN- $\gamma$ (Fig. 1) and IL-4 (Fig. 2) concentrations were significantly increased in the peripheral blood in the infected children when compared with the non-infected children $(7940 \pm 977.7$ vs. $4759.7 \pm 981.8 \mathrm{pg} / \mathrm{ml} ; 57061$ \pm 8922.2 vs. $30020.5 \pm 4013.8 \mathrm{pg} / \mathrm{ml} ; 870.1 \pm 209.1$ vs. $498.9 \pm 62.8 \mathrm{pg} / \mathrm{ml}$, respectively; $p<0.05)$. However, TNF- $\alpha$ (Fig. 1), IL-5 and IL-6 (Fig. 2) were less concentrated in the infected children compared to the non-infected children ( $4905 \pm 2152$ vs. $12456.7 \pm 2555.3 \mathrm{pg} / \mathrm{ml} ; 262720$ \pm 3880.4 vs. $784955.7 \pm 9918.5 \mathrm{pg} / \mathrm{ml} ; 919.5 \pm 221.4$ vs. $1850.2 \pm 418.2 \mathrm{pg} / \mathrm{ml}$, respectively; $p<0.05)$. IL-10 con-

Table 1. Characteristics of non-infected and infected children

\begin{tabular}{|c|c|c|c|}
\hline Study group & Sex & Age & Type of infection \\
\hline $\begin{array}{l}\text { No infected } \\
\text { children }(n=30)\end{array}$ & $\begin{array}{l}\text { female }(n=9) \\
\text { male }(n=21)\end{array}$ & $\begin{array}{c}\text { female }(8 \mathrm{~m}-5 \mathrm{y}) \\
\text { male }(7 \mathrm{~m}-5 \mathrm{y})\end{array}$ & no infection \\
\hline $\begin{array}{l}\text { Infected } \\
\text { children }(n=30)\end{array}$ & $\begin{array}{c}\text { female }(n=12) \\
\text { male }(n=18)\end{array}$ & $\begin{array}{l}\text { female }(9 \mathrm{~m}-5 \mathrm{y}) \\
\text { male }(8 \mathrm{~m}-5 \mathrm{y})\end{array}$ & $\begin{array}{c}\text { gastrointestinal (9) } \\
\text { (female } n=6 ; \text { male } n=3 \text { ) } \\
\quad \text { respiratory }(21) \\
(\text { female } n=6 ; \text { male } n=15 \text { ) }\end{array}$ \\
\hline
\end{tabular}




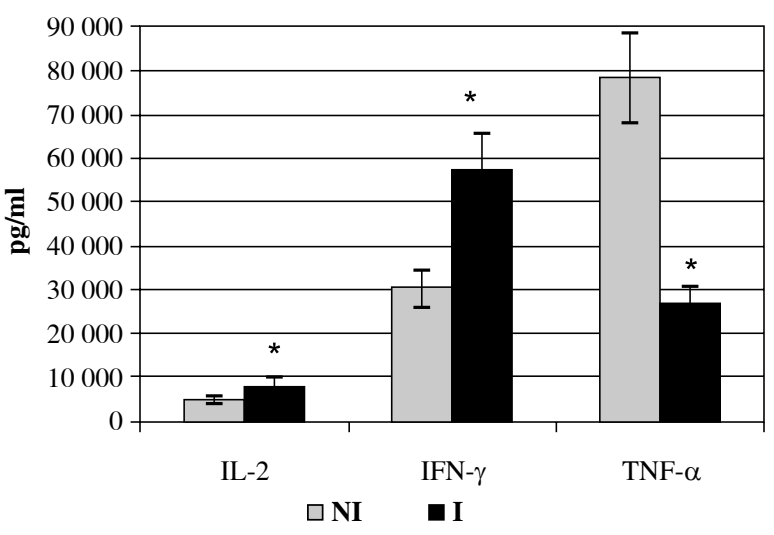

Data are expressed as the means standard errors;

$N I$ - non-infected children $(n=30)$

$I$ - infected children $(n=30)$

Statistically significant difference between non-infected and infected children: $I L-2, p<0.02 ; I F N-\gamma, p<0.01 ; T N F-\alpha, p<0.05$

Fig. 1. The concentrations of T1 cytokines and TNF- $\alpha$ in the peripheral blood of infected and non-infected children

centrations showed no statistically significant differences between the two groups.

Regarding differences with respect to the type of infection, it was observed that children with gastrointestinal infections showed higher TNF- $\alpha$ concentrations when compared to children with respiratory infections (8258.8 \pm 3792.3 vs. $2100 \pm 10 \mathrm{pg} / \mathrm{ml}$, respectively; $p<0.05$ ). However, children with respiratory infections showed increased levels of IL-4 $(870 \pm 209.1 \mathrm{pg} / \mathrm{ml})$, IL-5 $(2160 \pm 30 \mathrm{pg} / \mathrm{ml})$, IL-6 $(919.5 \pm 221.4 \mathrm{pg} / \mathrm{ml})$ and IL-10 $(754.7 \pm 132.4 \mathrm{pg} / \mathrm{ml})$ when compared to the patients with gastrointestinal infections. The latter group had non-detectable concentrations of these cytokines. IL- 2 and IFN- $\gamma$ concentrations showed no statistically significant differences with respect to the type of infection (Fig. 3).

The ELISA analysis for the detection of antibodies against specific pathogens demonstrated that five of the nine patients displaying symptoms of gastrointestinal infections were positive for $E$. coli antigens. Of these five patients, three were positive for enterohemorrhagic $E$. coli (EHEC O157:H7) antigens, and two were positive for EPEC antigens. None of the samples from the nine patients with gastrointestinal infections had absorbance values indicating the presence of antibodies against the outer membrane proteins of Salmonella typhi.

Of the 21 patients with symptoms of respiratory infections, 14 were positive for antibodies against Staphylococcus aureus antigens, and 4 were positive for Klebsiella pneumoniae antigens. Only three patients did not react positively for any of the antibodies against the bacterial species analysed in the present study. No statistically significant differences were found regarding the cytokine analysis when comparing the type of infectious agent.

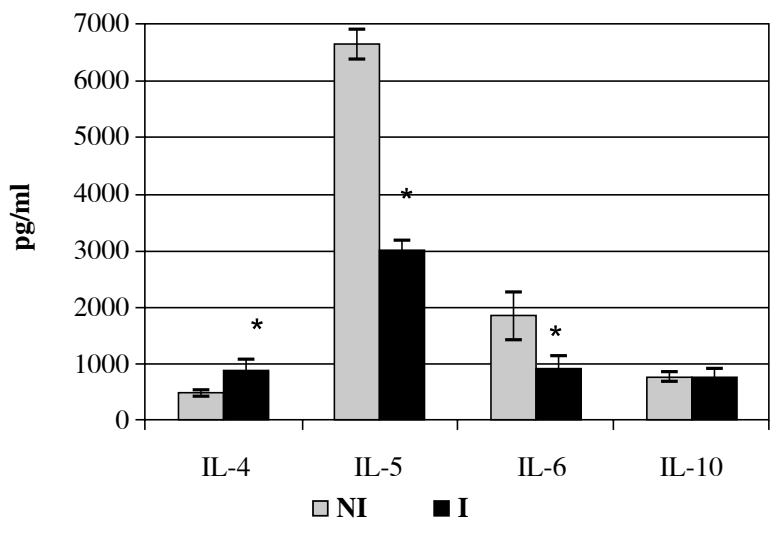

Data are expressed as the means standard errors;

$N I$ - non-infected children $(n=30)$

$I$ - infected children $(n=30)$

Statistically significant difference between non-infected and infected children: $I L-2, p<0.02 ; I F N-\gamma, p<0.01 ; T N F-\alpha, p<0.05$

Fig. 2. The concentrations of $\mathrm{T} 2$ cytokines in the peripheral blood of infected and non-infected children

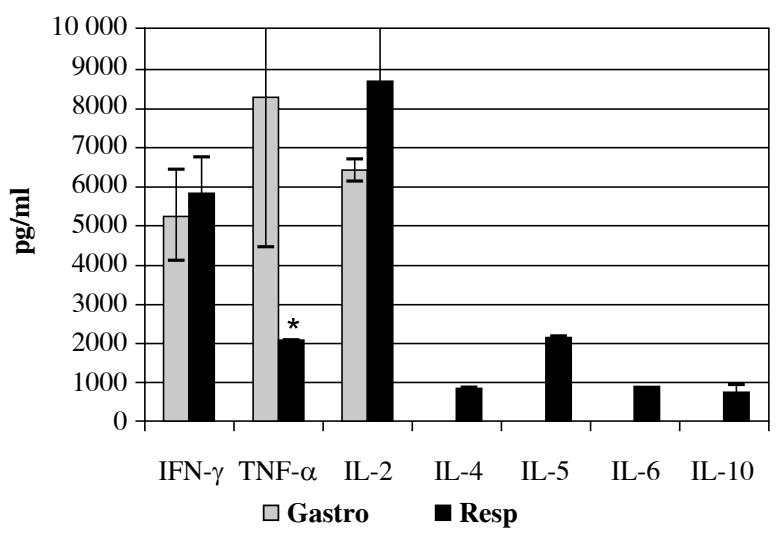

Data are expressed as the means standard errors;

$N I$ - non-infected children $(n=30)$

$I$ - infected children $(n=30)$

Statistically significant difference between non-infected and infected children: $I L-2, p<0.02 ; I F N-\gamma, p<0.01 ; T N F-\alpha, p<0.05$

Fig. 3. The concentrations of $T 1 / T 2$ cytokines and TNF- $\alpha$ in patients with bacterial infections, organized by the type of infection

\section{Discussion}

Respiratory and gastrointestinal infections are public health issues in developing countries, which primarily affect children. It has been reported that, during infections, the adaptive immune response can trigger a $\mathrm{T} 1$ (cellular) or T2 (humoral) response, depending on the aetiological agent [6].

According to the data obtained in the present study, children presenting with bacterial infections showed increased IFN- $\gamma$, IL-2 and IL-4 concentrations when com- 
pared with non-infected children. However, the cytokine analysis regarding the type of infection revealed that children with gastrointestinal infections showed increased TNF- $\alpha$ concentration. However, IL- 2 and IFN- $\gamma$ showed no statistically significant differences when comparing children with gastrointestinal infections with children with respiratory infections. A remarkable finding is that children with gastrointestinal infections did not appear to have any T2 response cytokines (IL-4, IL-5, IL-6 and IL-10) in their peripheral blood. Thus, it can be said that, for paediatric patients presenting with gastrointestinal infections in the present study, there was a predominant cellular (T1) immune response and an increased concentration of circulating TNF- $\alpha$.

Tumor necrosis factor $\alpha$ is a cytokine that possesses pro-inflammatory properties and pleiotropic effects in several cell types. The presence of polysaccharides is a stimulus for the production of this cytokine; thus, it is considered an important mediator in the response against gram-negative bacteria. High TNF- $\alpha$ concentration in some children could be explained by the fact that this cytokine has been strongly associated with the resolution of infections caused by EPEC, by activating macrophages and increasing their phagocytic activity [7]. In the present study, EPEC was found in some of the patients with gastrointestinal infections. However, in a separate study [8], it was observed that the outer membrane vesicles of $E$. coli triggered the cellular immunity mediated by $\mathrm{T}$ lymphocytes through INF- $\gamma$ and IL-17 synthesis, with the humoral response being less important.

Interferon $\gamma$ induces direct antimicrobial mechanisms, including macrophage activation and opsonisation. Moreover, it regulates antigen presentation and processing, directs leukocyte attraction and regulates the growth, maturation and differentiation of several cell types [9, 10]. Interleukin 2 stimulates the proliferation of CD4+, CD8+ and NK cells, increases the cytolytic activity of cells, stimulates IFN- $\gamma$ production and is a growth and differentiation factor [11]. The presence of TNF- $\alpha$, IL-2 and INF- $\gamma$ suggests the existence of a $\mathrm{T} 1$ response in children with gastrointestinal infections, in the present study.

However, children with respiratory infections showed low TNF- $\alpha$ and T1 cytokine (INF- $\gamma$ and IL-2) concentrations, similar to those observed for children with gastrointestinal infections. Additionally, children with respiratory infections showed variable IL-4, IL-5, IL-6 and IL-10 concentrations, suggesting the presence of both responses (T1/T2) for the resolution of the infectious process in children with respiratory infections. It has been reported that, in laboratory animals infected with $S$. aureus, alveolar macrophages produce the pro-inflammatory cytokines TNF- $\alpha$ and IL- 6 in response to the infection. Additionally, repeated exposure to $S$. aureus initiated a Th1/Th17 cellular response, where the Th1 and Th17 responses were determined by the presence of IFN- $\gamma$ and IL-17, respec- tively [12]. Likewise, in the blood of mice vaccinated with recombinant $S$. aureus and Candida albicans antigens, it was observed that Th1 and Th17 lymphocyte responses were triggered with the production of IFN- $\gamma$ and IL-17, respectively. The response, in turn, increased phagocytosis to act against both types of microorganisms [4].

Additionally, a T1/T2 response has been observed in viral respiratory infections. In children infected with Respiratory Syncytial Virus (RSV), the presence of the T1/ $\mathrm{T} 2$ response was studied through cytokine concentrations (IL-2, IFN- $\gamma$ and TNF- $\alpha$, and IL-4, IL-6 and IL-10, respectively) to predict the severity of the disease and possible sequential episodes. It was observed that the concentrations of the cytokines IL- 6 , IL-10 and IFN- $\gamma$ significantly decreased as time passed and that the correlation was changed towards a T2 response by the presence of IgE in the children's serum [13]. Thus, a similar immune response was found in the present study, given that, at the moment of hospitalisation, both immune responses (T1/ T2) were detected in children with respiratory infections.

A previous study performed to determine the inflammatory cytokine expression pattern in children with a severe Streptococcus pyogenes infection demonstrated that patients with invasive infections have significantly higher concentrations of IFN- $\gamma$, IL-1, IL-6, IL-8, IL-10 and IL-18 when compared both to children who have non-invasive infections and healthy children. In children with massive infections, T1 and T2 cytokines were observed, in addition to those for innate immunity [14]. These results are comparable to those reported in the present study for children with respiratory infections.

It is important to note that the humoral response triggers antibody synthesis, which contributes to the defence against extracellular pathogens in three different ways: first, through antibody binding to the pathogen, toxins and virulence factors to neutralise their effects on the host; second, through antibody binding to the bacterial surface as opsonins, facilitating phagocytosis; and third, by triggering the activation of the classical complement pathway [15]. Although the present study did not determine the presence of antibodies, the fact that $\mathrm{T} 2$ cytokines were present indicates that they were present in the resolution of the respiratory infections in infected children.

The qualitative and quantitative differences between the cytokines produced during respiratory and gastrointestinal infections may be due to the bacteria present in each of the infection types, which activate the immune system cells through different Toll-like receptors (TLRs). Each TLR has a different intracellular signalling process and recruits specific groups of adaptor molecules, which leads to the activation of different transduction pathways and, finally, to specific cytokine secretion patterns [16].

However, non-infected patients in the present study showed high cytokine concentrations (TNF- $\alpha$, IL-5 and IL-6) when compared to the infected children. Some au- 
thors have related the presence of cytokines to stress situations in patients who were scheduled for cryptorchidism surgery and surgery for phimosis. It has been reported that the stress occurring prior to a surgery alters the immune system throughout the hypothalamic-pituitary-adrenal axis through the production of hormones and neurotransmitters, causing an unbalance of interleukins [17]. It has been corroborated that shot-term stress induces the production of pro-inflammatory cytokines. However, prolonged mental stress can affect the humoral response [18].

Other studies have observed that stress-influenced conditions can deeply suppress the immune response of blood lymphocytes, including the response to T cell mitogens, NK activity and IL-2 and interferon production. However, moderate intensity conditions can increase such responses [19].

\section{Conclusions}

In conclusion, the present study reveals that, on a peripheral level, there is an increase in the concentrations of several cytokines in paediatric patients with bacterial infections. According to the cytokine patterns observed, the data demonstrate that, in gastrointestinal infections, a $\mathrm{T} 1$ response is predominant, whereas in patients with respiratory infections, both types of responses (T1/T2) are present.

The authors declare no conflict of interest.

The authors would like to thank CONACyT, Mexico grants 311030 and 47905 (for Monika Palacios Martínez).

\section{References}

1. Pinto R, Arredondo S, Bono M, et al. (2006): T Helper 1/T Helper 2 cytokine imbalance in respiratory syncytial virus infection is associated with increased endogenous plasma cortisol. Pediatrics 117: e878-886.

2. Herring AC, Hernández Y, Huffnagle GB, Toews GB (2004): Role and development of Th1/Th2 immune responses in the lungs. Semin Respir Crit Care Med 25: 3-10.

3. Curtis JL. Cell-mediated adaptive immune defense of the lungs (2005): Proc Am Thorac Soc 2: 412-16.

4. Lin L, Ibrahim AS, Xu X, et al. (2009): Th1-Th17 cells mediate protective adaptive immunity against Staphylococcus aureus and Candida albicans infection in mice. PLoS Pathog 5: e1000703.

5. Kurstak E (1985): Progress in enzyme immunoassays: production of reagents, experimental design, and interpretation. Bull World Health Organ 63: 793-811.

6. Nakagome K, Dohi M, Okunishi K, et al. (2005): Antigen-sensitized CD4+CD62Llow memory/effector T helper 2 cells can induce airway hyperresponsiveness in an antigen free setting. Resp Res 6: 461-466.

7. Long KZ, Rosado JL, Santos JI, et al. (2010): Associations between Mucosal Innate and Adaptive Immune Responses and Resolution of Diarrheal Pathogen Infections. Infect Immun; 3: 1221-1228.
8. Kim OY, Hong BS, Park KS, et al. (2013): Immunization with Escherichia coli outer membrane vesicles. Protects bacteria-induced lethality via Th1 and Th17 cell responses. J Immunol 190: 4092-4102.

9. Decker T, Stockinger S, Karaghiosoff M, et al. (2002): IFNs and STATs in innate immunity to microorganisms. J Clin Inves 109: 1271-1277.

10. Schroder K, Hertzog PJ, Ravasi T, Hume DA (2004): Interferon- $\gamma$ : an overview of signals, mechanisms and functions. J Leuko Biol 75: 163-189.

11. Bachmann MF, Oxenius A (2007): Interleukin 2: from immunostimulation to immunoregulation and back again. EMBO Rep 8: 1142-1148.

12. Kim MR, Hong SW, Choi EB, et al. (2012): Staphylococcus aureus-derived extracellular vesicles induce neutrophilic pulmonary inflammation via both Th1 and Th17 cell responses. Aller 67: 1271-1281.

13. Gut W, Pancer K, Abramczuk E, et al. (2013): RSV respiratory infection in children under 5 y.o. - dynamics of the immune response Th1/Th2 and IgE. Przegl Epidemiol 67: $17-22$.

14. Wang SM, Lu IH, Lin YL, et al. (2008): The severity of Streptococcus pyogenes infections in children is significantly associated with plasma levels of inflammatory cytokines. Diagn Microbiol Infect Dis 61: 165-169.

15. Holtfreter S, Kolata J, Broker BM (2010): Towards the immune proteome of Staphylococcus aureus The anti-S. aureus antibody response. Int J Med Microbiol 300: 176-192.

16. Zimmermann C, Weber A, Mausberg AK, et al. (2012): T cell activation status determines the cytokine pattern induced by zymosan and bacterial DNA both in thymocytes and splenocytes. Clin Exp Immunol 172: 245-53.

17. Spenedi E, Chiasari A, Gaillard RC (2002): Neuroendocrine-immune interactions. Front Horm Res 29: 91-107.

18. Matalka KZ (2003): Neuroendocrine and cytokines-induced responses to minutes, hours and days of mental stress. Neuroendocrinol Lett 24: 283-292.

19. Sánchez SM, González GR, Cos PY, Macías AC (2007): Stress and immune system. Rev Cubana Hematol Inmunol Hemoter 23. Available at: http://scielo.sld.cu/scielo. php?script=sci_issuetoc \&pid=0864-028920070002 \&lng= es\& nrm=iso. 